\title{
ISOLAMENTO, IDENTIFICAÇÃO E SOROTIPAGEM DE CANDIDA ALBICANS A PARTIR DE SECREÇÃO VAGINAL (1)
}

\author{
Antonio Luengo GARCIA (?) \& Antonio Martins de SIQUEIRA (2)
}

\author{
R E S U M O
}

\begin{abstract}
Foram estudadas 104 anostras de secreçāo vaginal de mulheres com suspeita de candidiase segundo observaços clinicas, na cidade de Alfenas-MG. Encontrou-se $55,7 \%$ de positividade para Candida albicans, prevalecendo maior indice na raça werk 164\% de 25 amostras). sendo de 53.1\% (79 amostras), a positividade na raça branca. Em 14 gestantes. a pesquisa da levedura mostrou-se positiva na totalidade dos casos. A maioria das amostras positivas $(93,1 \%$ procedia de mulheres com idade compreendida entre 2040 anos. O uso de anticoncepcionais. antibióticos e presença de displasias cervicais mostraram se como fatores que contribuiram para maior incidencia do fungo. Das 58 amostras de $C$. albicans isoladas, $50(86,2 \%)$ pertenciam ao sorotipo "A", sendo $37(74 \%$ ) isoladas de mulheres da raça branca e $13(26 \%)$ da raça negra. Apenas 08 amostras $(13.8$ ") pertenciam ao sorotipo "B", sendo 05 $(11.9 \%$ isoladas a partir de mulheres da raça branca e $03(18.75 \%)$ da raca negra.
\end{abstract}

UNITERMOS: Candidiase: Candida albcans: Leveduras: Sorotipos

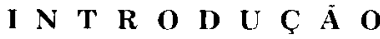

Sabe se que diversas especies de Candida podem ser encontradas em individuos normais. principalmente nas fezes, vagina, cavidade bu cal. urina e escarro (22).

Quando as condiçóes do hospedeiro mudam por diversos fatores, tais como diabetes, gravi dez. tratamentos prolongados com antibióticos ou corticosteróides, desnutriçáo. baixa das defe sas do individuo, uso de prótese dentária ou cardiaca. contato com enfermos de candidiase, $C$. albicans até entāo saprófita, torna se patogêni ca. multiplica-se, invade os tecidos do hospedei. ro disseminando-se ate chegar em raras ocasioes a tornar-se sistêmica (6).
Baseando-se nas propriedades aglutinantes de anti-soros preparados com várias amostras de $C$. albicans, esta espécie pode ser dividida em 2 sorotipos, "A"e "B". O sorotipo "A", antige nicamente mais complexo, possui antígenos co muns ao sorotipo " $B$ " além de antigenos pecu liares. A atividade aglutinante do anti-soro para o sorotipo "B" é completamente removida após absorção com células do sorotipo "A". O anti soro obtido com células do sorotipo "A" e absor vido com células do sorotipo " $B$ " é antigenicamente relacionado à $C$. tropicalis e o sorotipo "B" à C. stellatoidea $(8,9,10)$.

\footnotetext{
11) Trabalho realizado no Laboratorio de Sorologia da Fundacao de Ensino e Tecnologia de Alfenas (MG। e apresentado pelo primeiro autor, na Escola de Farmácia e Odontologia de Alfenas (MG para obtençao do grau de Especialista em Mierobiologia

(2) Laboratório de Sorologia da Fundaça de Ensino e Tecnologia de Alfenas. Campus Universitário. Rodovia MG 179 . Km 0. Caixa Postal 23. CEP 37130 Alfenas, Minas Gerais, Brasil
} 
GARCIA. A. L. \& SIQUEIRA, A. M. de - Isolamento, identificaçào e sorotipagem de Candida albicans a partir de secreçao vaginal. Rev. Inst. Med. trop. São Paulo, 30 (4): $270.273,1988$

\section{MATERIAL E MÉTODOS}

Foram coletadas em consultórios ginecoló gicos e laboratórios clínicos da cidade de Alfe nas-MG, 104 amostras de secreção vaginal de mulheres com suspeita de candidiase, segundo dados clínicos. Desse total, 79 eram provenientes de mulheres de raça branca e 25 de raça negra, e a faixa de idade variava entre 18 a 56 anos (Tabela l).

\section{TABELA 1}

Distribuicáo das pacientes de acordo com a faixa etária, e cor relaçào entre presença ou ausencia de $C$. culbicans e'm secrecao vaginal

\begin{tabular}{|c|c|c|c|}
\hline $\begin{array}{l}\text { FAIXA ETARIA } \\
\text { ranos }\end{array}$ & PACIENTES & POSITIVOS & NEGATIVOS \\
\hline $10 \longmapsto 20$ & $08,7,69 \%$ & $02(25,00 ;)$ & $06(75,00 \%)$ \\
\hline $2 \longmapsto 30$ & $68(65.38 \%)$ & $37\left(54.41^{\prime} ;\right)$ & $31(45,58 \%)$ \\
\hline $3 \longmapsto 40$ & $23\left(22.12^{\prime}\right)$ & $17(73.91 \%)$ & $06(26.09)$ \\
\hline $4 \longmapsto 50$ & $02(1.92 \%$ & $01\{50.00 \%)$ & $01(50,00 \%)$ \\
\hline $5 \longmapsto 60$ & $03(2.89 \%$ & $01(33.33 \%)$ & $02\left(66.66^{4 / 4}\right)$ \\
\hline TOTAL & 104 & $58(55.77 \%)$ & $46(44,23 \%)$ \\
\hline
\end{tabular}

No isolamento foi utilizado o meio seletivo preconizado por PAGANO et al. (17) e para iden tificaçāo utilizou-se: ágar fubá (7), para verificaçāo da formaçāo de clamidosporos através de cultivo em lâmina (3); solução de $1 \%$ de bactopeptona (14) e soro de cavalo para tubos germinativos (21).

Na obtenção de soros hiperimunes, foi utilizada suspensão celular de C. albicans sorotipo "A" cultivada em ágar Sabouraud, para inoculaçāo em coelhos machos pesando cerca de 3,5 $\mathrm{kg}$ segundo esquemas de HASENCLEVER \& MITCHELL (8) e SWEET \& KAUFMAN (20).

$\mathrm{O}$ anti-soro obtido e fracionado em sulfato de amônio a $33 \%$, foi absorvido com células de C. albicans sorotipo "B".

Este anti-soro absorvido, adicionado de timerosal na concentração fínal de 1:10000 e conservado sob refrigeração foi usado nas provas de aglutinação em lâmina, na qual se utilizou gama-globulina normal de coelho como controle.
Resultados positivos de aglutinaçāo eram considerados sorotipo "A", enquanto os negati. vos, sorotipo "B".

\section{RESULTADOS}

A maioria das amostras em que se isolou C. albicans é proveniente de pacientes entre as faixas etárias de 20-40 anos.

Quanto à raça, a maioria das mulheres pesquisadas eram de raça branca $(75,96 \%)$, mas o maior indice de positividade verificou-se na raça negra $(64 \%)$.

Em todas as mulheres grávidas pesquisadas (total de 14) houve positividade do exame para C.albicans.

Na Tabela 2, encontra-se a distribuiçào das pacientes estudadas de acordo com os dados clinicos. Dentre esses, o que apresentou maior número de casos positivos foi o uso de anticoncepcionais, vindo a seguir o uso de antibióticos e displasias cervicais

O resultado da sorotipagem das amostras e sua correlaçào com a raça das pacientes, está contido na Tabela 3 . Houve predominancia do

TABELA 2

Distribuiçào das pacientes para a presença de $C$ albicans em secreçào vaginal, de acordo com os dados clinicos

\begin{tabular}{llll}
\hline DADOS CLINICOS & POSITIVOS NEGATIVOS TOTAL \\
\hline Uso de anticoncepcional & $11(57,89 \%)$ & $08(42,11 \%)$ & 19 \\
Uso de antibióticos & $09(50,00 \%)$ & $09(50,00 \%)$ & 18 \\
Diabetes & 01 & 00 & 01 \\
Displasias cervicais & $07(58,33 \%)$ & $05(41,67 \%)$ & 12 \\
Condiloma & 01 & 00 & 01 \\
Sem dados clinicos & $35(55,55 \%)$ & $28(44,45 \%)$ & 63 \\
\hline
\end{tabular}

TABEI.A 3

Correlaçao entre sorotipos de C. albicans isoladas a partir de secreça vaginal, e raça das pacientes.

\begin{tabular}{lcc}
\hline RACA & SOROTIPO “A & SOROTIPO “B” \\
\hline Branca & $37(74,00 \%)$ & $05(62.50 \%)$ \\
Negra & $13(26,00 \%)$ & $03(37.50 \%)$ \\
\hline TOTAL & $50(86,20 \%)$ & $08(13,80 \%)$ \\
\hline
\end{tabular}


GARCIA, A. L. \& SIQUEIRA, A. M. de - Isolamento, identificaçáo e sorotipagem de Candida albicans a partir de secrecảo vaginal. Rev. Inst. Med. trop. Sảo Paulo, 30 (4): 270273,1988

sorotipo "A" na raça branca e de " $B$ " na raça negra.

\section{DISCUSSÃO}

Na mulher, a candidiase vaginal é manifes tação comum. Desde que a Candida albicans é um habitante normal da área vaginal, apenas evidências microscópicas nảo sảo suficientes pa ra demonstraçāo da infecção ativa (15).

A vulvovaginite determinada principalmen te por C. albicans é infecção frequente, predomi nando durante o período reprodutor da mulher. e uma incidencia menor na infância, puberdade e climatério (16).

Quanto a raça, embora nāo tenhamos ele mentos concretos que nos indique a razào do maior isolamento de C. albicans a partir de mu lheres da raça negra, tudo nos leva a crer que, um dos prováveis fatores seja a condição sócio e conômica das pacientes, pois condições precárias de higiene e caréncia nutricional favorecem o desenvolvimento da levedura.

Em todas as mulheres grăvidas pesquisadas, isolou-se C, albicans, pois durante a gravidez, decorrente do nivel elevado de estrogênio, au menta a quantidade de glicogênio na mucosa vaginal. com maior acidez, facilitando o crescimento da levedura $(1,18)$.

O uso de anticoncepcionais é um fator que riuito favorece o aparecimento de $C$. albicans. Segundo LACAZ et al. (15), JACKSON \& SPAIN (12) e DIDDLE et al. (4) tudo faz crer que o emprego de anticoncepcionais favoreça o crescimento de fungos leveduriformes na secreção vaginal. O uso de antibióticos constitui-se, também, num fator importante para a ocorrencia desse tipo de infecçāo. Segundo SEELING (19) no passado a frequencia de aparecimento de candidiase era muito escassa, até o aparecimento dos antibióticos de amplo espectro que constribuíram para o seu aumento. JEFFCOATE (13) diz que candi díase é mais freqüente nas mulheres portadoras de displasias cervicais, lesoes precursoras de carcinomas do colo do útero, e no presente trabalho encontramos 7 casos de mulheres portadoras de displasias cervicais com C. albicans.
A sorotipagem das amostras foi introduzida no presente trabalho principalmente com o propósito de torná-la rotina na identificação de $C$. albicans, devido à facilidade de emprego e inter. pretaçāo da mesma. Os resultados obtidos estào de acordo com os trabalhos de HASENCLEVER \& MITCHELL (11), DROUHET et al. (5) e AU. GER et al. (2).

Outros comentários poderiam ser feitos sobre o encontro diferencial dos sorotipos de $C$. albicans a partir do trato genital de pacientes com suspeita de candidíase, e um deles seria com relação à maior resisténcia do sorotipo " $B$ " a certos agentes antifúngicos, pois segundo DROUHET et al. (5) e AUGER et al. (2), essa resistência indicaria maior prevalência de infecçōes resistentes ao referido sorotipo.

\section{SUMMARY}

ISOLATION, IDENTIFICATION AND SE. ROTYPING OF CANDIDA ALBICANS FROM VAGINAL SECRETION.

According to clinical observations in the city of Alfenas-MG, 104 samples of vaginal secretion in women with suspected candidiasis were studied. $55,7 \%$ of positivity were found for Candida albicans, prevailing greater rate in black people $164 \%$ of 25 samples) than in white people, the least positive in the total of cases. The majority of the positive samples $(93.1 \%)$ belonged to women within the ages of 20 and 40 . The use of contraceptives, antibiotics and the presence of cervical displasy were the factors that contributed to the greatest incidence of the fungi. Of the 58 samples of $C$. albicans isolated, $50(86,2 \%)$ belonged to the serotype " $A$ ", of these $37(74 \%)$ were isolated from white women and $13(26 \%)$ of black ones. Only 08 samples $(13.8 \%)$ belonged to the serotype " $B$ ", 05 of the $08(11.90 \%)$ were isolated from white women and $03(18.75 \%)$ of the black women.

REFERĖNCIAS BIBLIOGRAFICAS

ALMEIDA, F.; LACAZ, C. S.; ANDREUCCI, D. \& BAR ROS, O. - Frequencias de cogumelos na vagina e impor táncia desses microorganismos como agentes de vulvova ginites. Rev. Inst. A. Lutz (S.Paulo), 6: 149 182, 1946. 
GARCIA. A. L. \& SIQUEIRA. A. M. de - Isolamento, identificaçāo e sorotipagem de Candida alhicans a partir dt secreça vaginal. Rev. Inst. Med. trop. Sáo Paulo, 30 (4): 270273.1988

2. AUGER. P : DUMAS, C \& JOLY. J - A study of 666 strains of Candida aloicans. Correlation between sero type and susceptibility to 5 fluorocytosine J. infect. Dis., 139: 590594,1979

3. DALMAU, L. M. - Remarques sur la technique myeolo gique. Ann. Parasit. hum. comp., i: 536 545, 1929

4. DIDDLE, A. W., GARDNER, W. H.: WILLIAMSON, P. J \& O'CONNOR. K. A. - Oral contraceptive medications and vulvovaginal candidiasis, Obstet. Gynec., 34 : 373377. 1969

5. DROUHET, E.; MERCIER SONEY, L. \& MONTPLAI SIR, S. - Sensibilite et resistence des levures pathogenes aux 5 fuoropirimidines. I - Relation entre les phenotypes de resistence à la 5 fluorocytosine. le serotipe de C. albicans et l'ecologie de differentes species de Candiala dori gine humaine. Ann. Microbiol., 126B: 25 39, 1975

6. FEO.M. - Diagnostico rápido de C. albicans. Rev. Lat.-amer. Microbiol., 15: 217218,1973

7. GORDON, M. A.; BRADLEY, E. G. \& GRANT, V. O -The influence of corn meal agar upon chlamydospore pro duction by Candida albicans. J. Lab. clin. Med., 40: 316-320, 1952.

8. HASENCLEVER. H. F. \& MiTCheLL. W. O. - Antigenic studies of Candida. I -. Obscrvation of two antigenic groups in Candida abicans. J. Bact., 82: 570573.1962

9. HASENCLEVER. H F \& MITCHELL. W. O. - Antigenic studies of Candida. II -- Antigenic relation of Candidaalbicans group A and group B to Candida stellatoidea and Candida tropicalis. J. Bact., 82: $574577,1961$.

10. HASENCLEVER, H. F. \& MITCHELL. W. O. - Antigenic studies of Candida. III Comparative pathogenicity of Candida albicans group A. group B and Candida stellatoidea. J. Bact., 82: 578581,1961

11. HASENCLEVER. H. F. \& MITCHELL, W. O. - Antigenie studies of Candida. IV -... The relationship of the antigenic groups of Candida albicans to their isolation from various clinical specimens. Sabouraudia, 2: $201240,1963$.

12. JACKSON T. L. \& SPAIN, W. T. - Comparative study of combined and sequential antiovulatory therapy on va ginal moniliasis. Amer. J. Obstet, Gynec., 101: 11341136. 1968 .
13. JEFFECOATE N - Ginecologia. Bumos Aires Intu Medica. 1971.

14. JOSHI K R : GAVIN J B \& BREMNER D A Th formation of germ tube by Candida albiodns in varionis peptone media. Sahouraudia, 11:259262.1973

15. LACAZ. C. S.: SALEBIAN, A.: MENDES. M. IS TAKA HASHI, N. \& NAGAO, M. T - Eeologia das leverduy: do género Candida. In LACAZ, C. S.. org ... Candiduase Sào Paulo, EPU, EDUSP. 1980 p.4754.

16. MATHUR, S.: VIRELLA. G.: KOISTINEL. I HOPCFF III E O MAHVI T A \& FUDENBERG II H HUmu, immunity in vaginal candidiasis Infect. Immun. 15: 15: 287294 . 1977 .

17. PAGANO, J : LEVIN, J. D. \& TREJO, W. -.. Diagnostir medium for differentiation of species of candida In WELCH, H. \& MARTIN IBANEZ. F.. ed - - Antibiotics annual, 195\% 1958. New York. Medical Eneyelopedia 1958. p. 137143.

18. SALVATORE, C. A -- Candidiase vulvovaginal. In LA CAZ, C. S., org. - Candidiase, Säo Paulo. EPU: EDUSP 1980, p. 113120

19. SEELING, M. S. - The role of antibjotics in the pathoge nesis of Candida infections Amer, J. Med., 40: 887017. 1966

20. SWEET, C. E. \& KAUFMAN. L. - Application of agglu tinins for the rapid accurate identification of medically important Candida species. Appl. Microbiol., 19: 830836 1970

21 TASCHDJIAN. C. L. BURCHALL. J J. \& KOZIN. P

Rapid identification of candida alhueans by filtmur tation in serum and serum substitutes. Amer. J. Dis. Child. $19: 212215,1960$

22. TASCHDJIAN, C. L.: KOZIN P. J \& TONI. E. F - - Oppo tunistic yeast infection with special reference to Candi diasis. Ann. N. Y. Acad. Sci., 174: $606622,1970$.

Recebido para publicacào em 04031988 